\title{
APLIKASI MULTIPLATFORM PENGENDALI DAN PEMONITOR PERANGKAT LISTRIK PADA MINIATUR SMART HOME
}

\author{
Murie Dwiyaniti' ${ }^{1}$ Idhar Tio Atmaja², Yunas Firdaus ${ }^{3}$, Heru Noveansyah ${ }^{4}$ \\ ${ }^{1234}$ Program Studi Teknik Otomasi Listrik Industri, Teknik Elektro, Politeknik Negeri Jakarta, Jl. Prof. Dr. G.A \\ Siwabessy, Kampus Baru UI, Depok, 16424, Indonesia \\ e-mail: murie.dwiyaniti@elektro.pnj.ac.id
}

Diterima : 20 Agustus 2019. Disetujui : 16 September 2019. Diterbitkan: Oktober 2019

\begin{abstract}
Smart home is a combination of technology and services in the home environment that aims to improve the efficiency, comfort and safety of its inhabitants. One of the important things in a smart home is that the homeowner can control and monitor the electrical devices in the house both locally and online by using a smart phone and laptop or PC. This research develops a miniature smart home control system with a multiplatform monitor system. The electrical devices and sensors in the smart home are integrated with a Raspberry Pi controller and multiplatform monitor system namely SCADA, HMI Droid, and Web IoT. Local communication uses the Modbus protocol while online communication uses the Internet of things technology. Thus the homeowner can choose the most affordable access to control and monitor his home. As a result, multiplatform systems on miniature smart home can work in accordance with the specified job description. However, SCADA and HMI connectivity are cut off at a distance of more than 11 meters, while the IoT web can continue to function without any distance barriers while connected to the internet. Average response time on cayenne web 6.55 seconds, droid HMI 0.50 seconds, and SCADA 0.77 seconds.
\end{abstract}

Keywords: smart home, SCADA, HMI, Web IoT, control

\section{ABSTRAK}

Smart home merupakan gabungan antara teknologi dan pelayanan pada lingkungan rumah yang bertujuan meningkatkan efesiensi, kenyamanan dan keamanan penghuninya. Salah satu hal penting dalam smart home adalah pemilik rumah dapat mengontrol dan memonitor perangkat listrik yang ada di dalam rumah baik secara lokal maupun online dengan menggunakan perangkat smart phone dan laptop atau pc. Penelitian ini mengembangkan sebuah sistem kontrol miniatur smart home dengan sistem monitor yang multiplatform. Perangkat listrik dan sensor dalam smart home diitegrasikan dengan sebuah pengendali Raspberry Pi dan sistem monitor multiplatform yaitu SCADA, HMI Droid, dan Web IoT. Komunikasi lokal menggunakan protocol Modbus sedangkan komunikasi online menggunakan teknologi Internet of things. Dengan demikian pemilik rumah dapat memilih akses yang paling terjangkau untuk mengontrol dan memonitor rumahnya. Hasilnya, sistem multiplatform pada miniatur smart home dapat bekerja sesuai dengan deskripsi kerja yang ditentukan. Namun konektifitas SCADA dan HMI terputus pada jarak lebih dari 11 meter, sedangkan web IoT dapat terus berfungsi tanpa ada hambatan jarak selama terkoneksi dengan internet. Rata-rata respon time pada web cayenne 6.55 detik, HMI droid 0,50 detik, dan SCADA 0,77 detik.

Katakunci: smart home, SCADA, HMI, Web IoT, kontrol

\section{PENDAHULUAN}

Smart home memiliki beberapa manfaat seperti memberikan kenyamanan yang lebih baik, keselamatan dan keamanan yang lebih terjamin, dan menghemat penggunaan energi listrik [1]. Sistem smart home mengintegrasikan semua peralatan listrik yang ada di rumah dengan sebuah mikro komputer dan proses pengontrolan serta pemantauan 
dilakukan secara jarak jauh dengan mobile device selama ada koneksi internet.

Beberapa penelitian tentang smart home menggunakan Raspberry pi sebagai kontroler antara lain pengontrolan lampu berbasis server web [2], dan smartphone android [3], aplikasi rumah pintar pengendali peralatan elektronik rumah tangga berbasis web [4], sistem keamanan ruangan [5] dan akses kontrol pintu garasi otomatis menggunakan Raspberry pi berbasis android [6]. Sedangkan penelitian smart home berbasis Internet of Things telah dilakukan antara lain automation smarthome [7], keamanan dan privasi [8], dan IoT smar thome dengan platform LabVIEW [9]. Namun semua penelitian ini hanya mengontrol maksimum tiga perangkat listrik dan memiliki satu platform sistem monitoring. Belum ada penelitian yang menggunakan multiplatform. Sehingga kami mengembangkan sistem pengontrol dan pemonitor pada smart home yang multiplatform, yaitu Modbus dan IoT.

Protocol Modbus digunakan sebagai media untuk menghubungkan Raspberry pi dengan SCADA (Vijeo Citect) dan smartphone (HMI Droid). Sedangkan protocol IoT sebagai media untuk menghubungkan Raspberry pi dengan web IoT (Cayanne).

Perangkat listrik dan sensor yang dikontrol pun sangat lengkap terdiri dari lampu, power outlet, power window, sistem keamanan RFID, sistem keamanan motion, sistem keselamatan kebakaran dari kebocoran gas, garasi, lift, suhu ruangan, dan kipas.

Integrasi semua perangkat listrik dengan sistem monitor yang multiplatform menjadikan sistem ini cukup kompleks. Namun, sistem ini dapat memberikan kemudahan bagi pemilik rumah untuk memilih ataupun menggunakan sistem kontrol dan monitor sesuai dengan kebutuhan. Jika berada dalam lingkungan rumah cukup menggunakan HMI Droid ataupun SCADA yang tidak menggunakan internet sehingga menghemat pulsa internet. Namun jika pemilik rumah berada jauh dari rumah atau berpergian dapat menggunakan web IoT yang terhubung dengan internet.

\section{METODE PENELITIAN}

Metode penelitian yang digunakan adalah rancang bangun sistem yang terdiri dari beberapa tahap, yaitu:

1. Tahap perancangan sistem smart home dalam bentuk layout atau tampilan prinsip kerja smart home.

2. Tahap pembuatan pemrograman sistem kontrol dan protocol komunikasi dengan bahasa pemograman python. Serta membuat tampilan SCADA (Vijeo Citect), HMI Droid, dan Web IoT (Cayanne) untuk memonitor proses kerja sistem smart home.

3. Tahap pengujian kinerja sistem kontrol pemograman dengan mengaplikasikan ke miniatur smart home serta menguji komunikasi dan kecepatan respon SCADA, HMI Droid, Web IoT saat monitoring dan remote control sistem smart home.

4. Tahap analisa data

Pada penelitian ini, smart home dibuat dalam bentuk miniatur dengan ukuran $24 \times 50 \times 30 \mathrm{~cm}$ yang dilengkapi dengan berbagai perangkat listrik seperti terlihat pada Gambar 1.

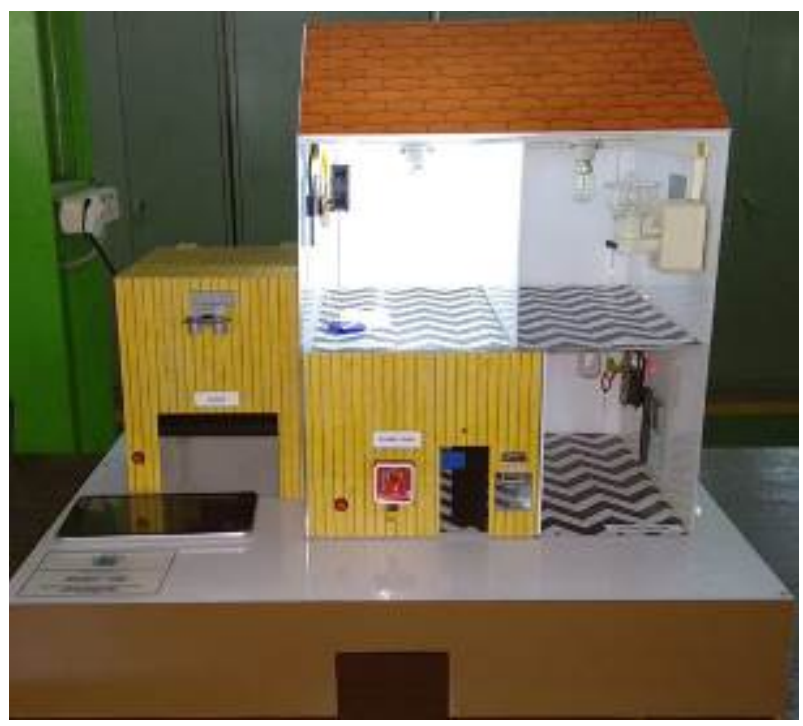

Gambar 1. Miniatur smart home

Tata letak perangkat listrik pada smart home dapat dilihat pada Gambar 2. Semua 
perangkat ini dapat dikontrol dan dimonitor dengan beberapa mode yaitu dengan SCADA pada PC, HMI Droid pada smartphone dan WEB IoT cayenne secara online. Semua terintegrasi dalam sebuah kontroler Raspberry pi seperti terlihat pada Gambar 3.

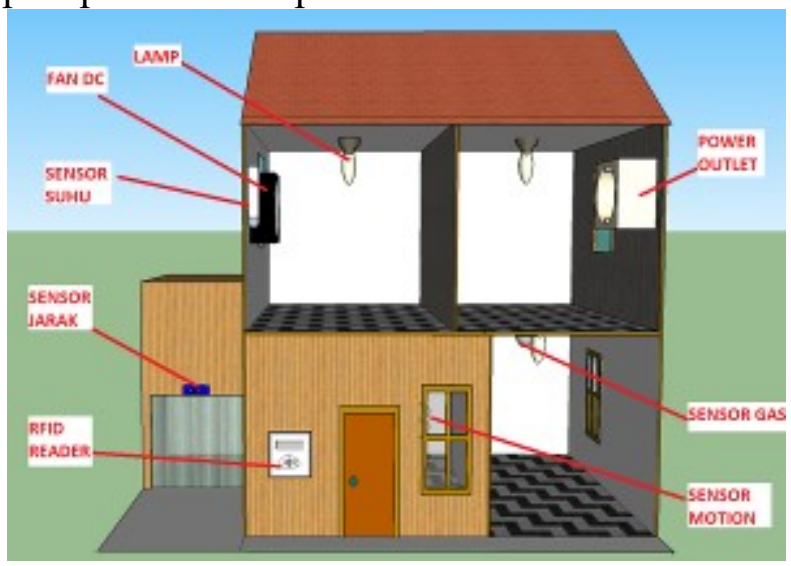

Gambar 2. Tata letak perangkat listrik

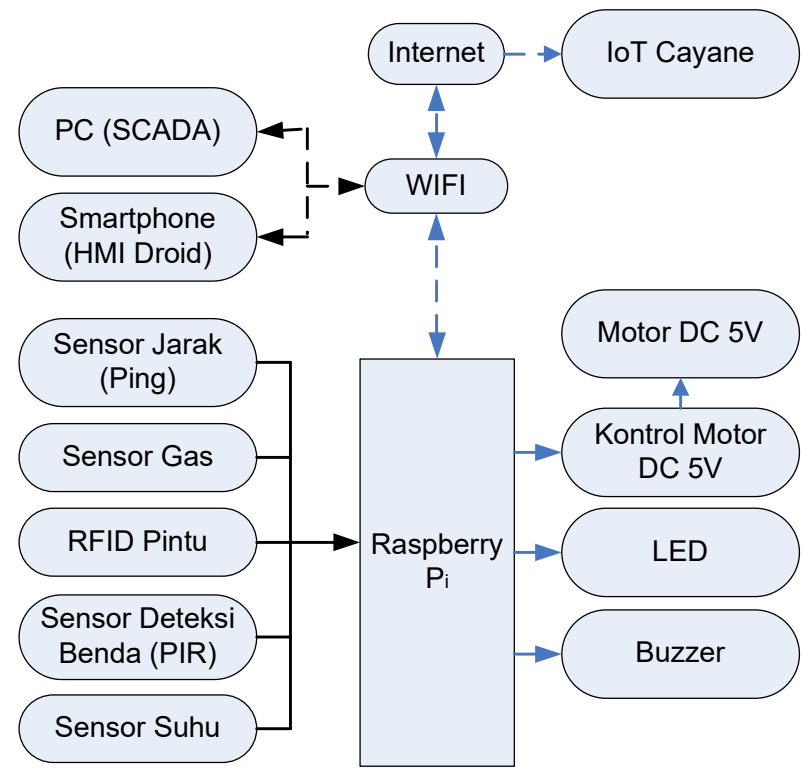

Gambar 3. Diagram blok sistem control dan monitor smart home

Koneksi antara kontroler dengan sistem monitor multiplatform menggunakan wifi. Output kontroler berupa:

1. Motor DC $5 \mathrm{~V}$ yang digunakan untuk menggerakkan kipas angin (AC), power window dapur, dan pintu garasi. Kecepatan dapat diatur melalui smartphone/pc dengan menggunakan slider dimmer.
2. Buzzer sebagai alarm apabila terjadi gangguan. Smartphone/pc dapat memberikan instruksi untuk mematikan buzzer.

3. Relay sebagai interface untuk On/Off lampu LED pada ruang tamu, lampu dapur, power outlet.

Sedangkan input kontroler berupa:

1. Sensor jarak ultrasonik yang berfungsi untuk membuka dan menutup pintu garasi.

2. Sensor deteksi benda (PIR) yang berfungsi untuk sistem keamanan pada smart home dari pencuri.

3. Sensor gas yang berfungsi sebagai sistem pendeteksi gas berlebih pada kompor untuk menghindari kebakaran karena gas bocor.

4. Sensor suhu untuk mendeteksi suhu ruangan.

5. RFID yang berfungsi sebagai sistem keamanan dan akses kontrol pemilik rumah.

\section{HASIL dan PEMBAHASAN}

Hasil dan pembahasan diperoleh dengan melakukan pengujian, antara lain tampilan SCADA, HMI Droid, dan web IoT, konektivitas integrasi sistem, dan respon time sistem.

\subsection{Tampilan Smart Home}

Miniatur smart home memiliki tampilan yang user friendly pada tiga mode monitor, yaitu SCADA dan HMI Droid (Gambar 4) dan web IoT (Gambar 5). Untuk keamanan sistem, hanya pemilik rumah atau orang tertentu saja yang mempunyai user name dan password yang dapat mengakses sistem ini.

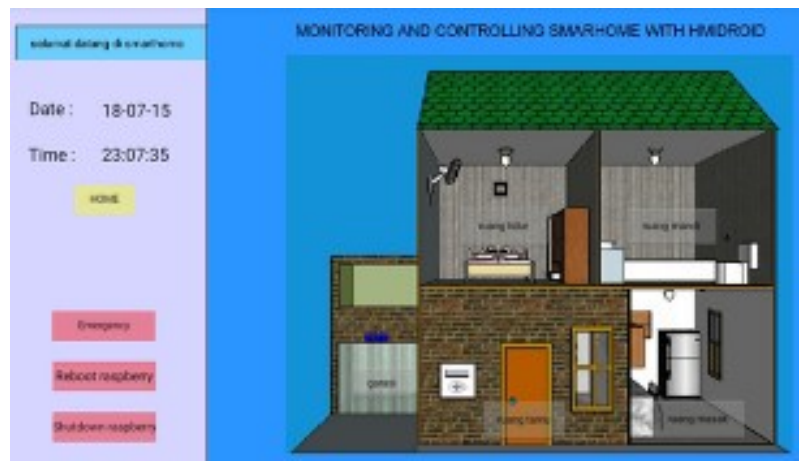


Gambar 4. Tampilan SCADA dan HMI Droid

Terlihat pada Gambar 4, bahwa tampilan SCADA dan HMI Droid sangat mirip dengan miniatur smart home. Untuk mengontrol dan memonitor peralatan listrik di masing-masing ruang, pemilik rumah dapat mengklik namanama ruang pada tampilan tersebut.

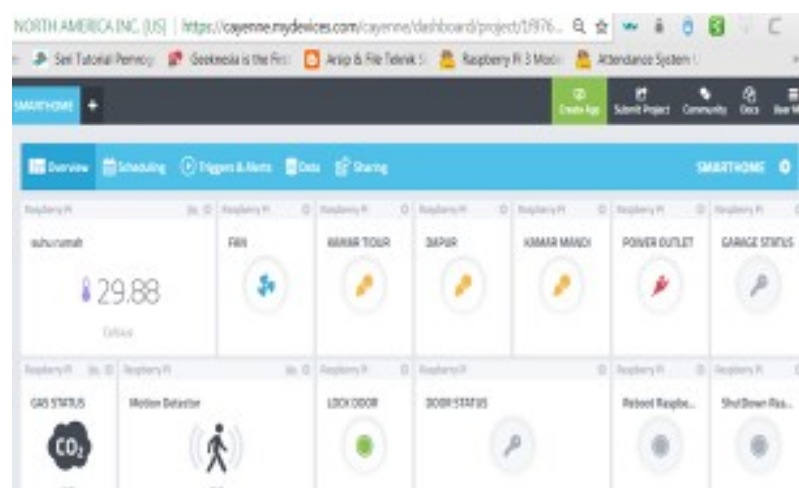

Gambar 5. Tampilan web IoT Cayane

Pada web IoT dengan platform Cayane tidak dapat menampilkan bentuk miniatur smart home. Tampilan hanya berupa simbol peralatan listrik seperti pada Gambar 5.

\subsection{Pengujian Kesesuaian Deskripsi}

Pengujian ini bertujuan untuk melihat apakah perangkat listrik yang telah terintegrasi dengan pengendali Rasberry pi, SCADA, HMI Droid, dan web IoT Cayane berfungsi dengan baik sesuai dengan deskripsi kerja yang diinginkan. Contoh pengujian kesesuaian deskripsi untuk lampu pada ruang tidur seperti terlihat pada Gambar 6 a,b,c. dan d.

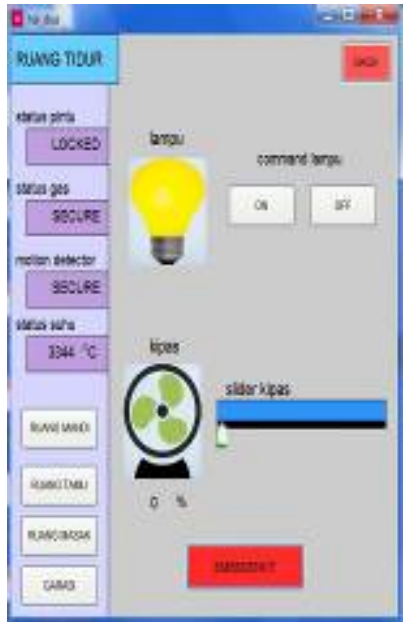

(a)

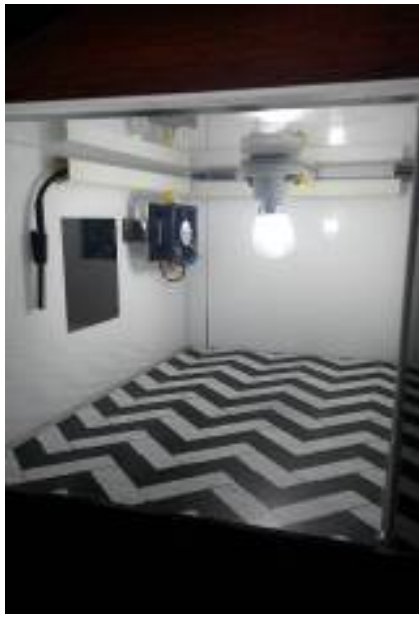

(b)

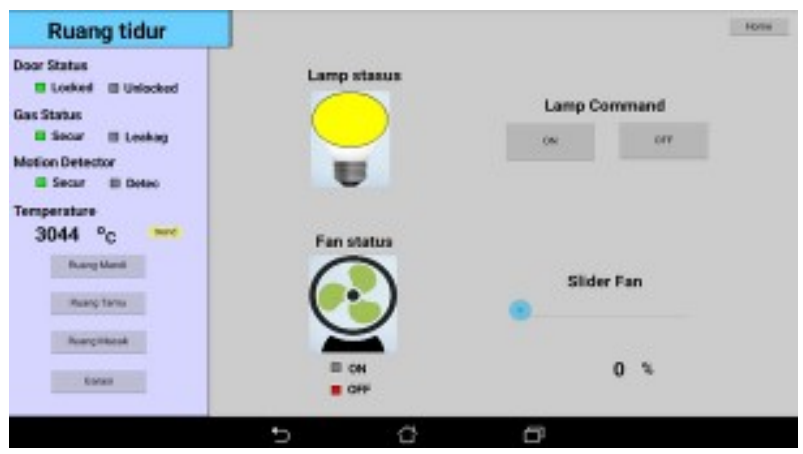

(c)

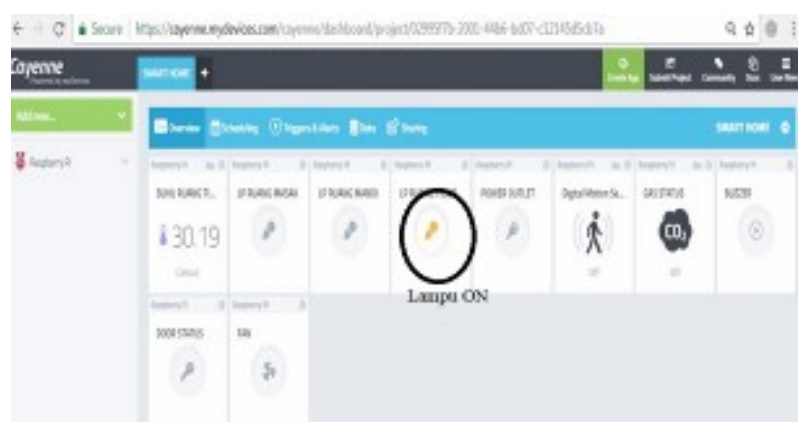

(d)

Gambar 6. Tampilan pada (a) SCADA, (b) Real plant, (c) HMI Droid, dan (d) web IoT

Ketika lampu ruang tidur dinyalakan melalui SCADA (gambar 6a), lampu pada miniatur smart home juga menyala (gambar 6b). Begitu pula lampu pada layar smartphone (gambar 6c) dan web IoT (gambar 6d).

Hal ini membuktikan bahwa sistem telah bekerja dengan baik sesuai dengan deskripsi yang diinginkan. 


\subsection{Pengujian Fungsi Peralatan Listrik}

Pengujian ini dilakukan untuk mengetahui apakah peralatan listrik yang digunakan berfungsi dengan baik. Hasil pengujian dapat dilihat pada Tabel 1 .

Pada Tabel 1 terlihat bahwa semua peralatan berfungsi dengan baik. Hal ini ditandai dengan adanya tegangan pada peralatan listrik.

Tabel 1. Hasil pengujian perangkat listrik

\begin{tabular}{|c|c|c|c|c|}
\hline \multirow{2}{*}{ No } & \multirow{2}{*}{ Command } & \multicolumn{2}{|c|}{ Kondisi } & \multirow{2}{*}{ Keterangan } \\
\hline & & ON & OFF & \\
\hline 1 & $\begin{array}{c}\text { Lampu Ruang } \\
\text { Masak }\end{array}$ & $235 \mathrm{VAC}$ & 0 & Baik \\
\hline 2 & $\begin{array}{c}\text { Lampu Ruang } \\
\text { Mandi }\end{array}$ & $235 \mathrm{VAC}$ & 0 & Baik \\
\hline 3 & $\begin{array}{c}\text { Lampu Ruang } \\
\text { Tidur }\end{array}$ & $235 \mathrm{VAC}$ & 0 & Baik \\
\hline 4 & Kotak Kontak & $235 \mathrm{VAC}$ & 0 & Baik \\
\hline 5 & $\begin{array}{c}\text { Push Button } \\
\text { Garasi }\end{array}$ & 0 & $2,2 \mathrm{VDC}$ & Baik \\
\hline 6 & PING Garasi & 0 & 0 & Baik \\
\hline \multirow{3}{*}{7} & \multirow{3}{*}{ Fan } & $1,4 \mathrm{VDC}$ & \multirow{3}{*}{0} & $40 \%$, Sesuai \\
\hline & & $1,8 \mathrm{VDC}$ & & $70 \%$, Sesuai \\
\hline & & $3,2 \mathrm{VDC}$ & & $100 \%$, Sesuai \\
\hline 8 & Suhu & $3,3 \mathrm{VDC}$ & 0 & Baik \\
\hline 9 & Motion Detector & $3,2 \mathrm{VDC}$ & 0 & Baik \\
\hline 10 & Gas Sensor & 0 & $2,3 \mathrm{VDC}$ & Baik \\
\hline 11 & Push Button Pintu & 0 & $2,2 \mathrm{VDC}$ & Baik \\
\hline 12 & RFID Door & $3,2 \mathrm{VDC}$ & $1,6 \mathrm{VDC}$ & Baik \\
\hline 13 & Lift & $3,3 \mathrm{VDC}$ & 0 & Baik \\
\hline 14 & Jendela & $3,3 \mathrm{VDC}$ & 0 & Baik \\
\hline 15 & Buzzer & $2,6 \mathrm{VDC}$ & 0 & Baik \\
\hline
\end{tabular}

\subsection{Pengujian Koneksitivitas}

Koneksi antara kontroler dengan sistem monitor multiplatform menggunakan wifi sehingga jarak dan kecepatan internet sangat berpengaruh pada sistem.

Multiplatform dengan dua protocol yaitu Modbus TCP/IP dan GPIO pin. Modbus TCP/IP digunakan sebagai media komunikasi pada SCADA dan HMI Droid. Sedangkan GPIO pin untuk penghubung Raspberry pi dengan web IoT.

Dalam penggunaan Modbus TCP/IP, diperlukan pemrograman pada server dan client. Modbus server berisi alamat IP Raspberri pi. Sedangkan Modbus client merupakan media penghubung antara sensor dan perangkat listrik yang telah terinstalasi pada raspberry pi dengan HMI Droid dan SCADA. Contoh penulisan alamat Modbus client terlihat pada Gambar 7, yaitu: $\mathrm{rr}=$ client.write register(0,50), artinya penulisan data ke analog integer pada HMI Droid dan SCADA. Dimana 0 adalah alamat register dan 50 adalah nilainya.

$\mathrm{rr}=$ client.read_holding_registers $(0,5)$ adalah range alamat register (tipe data integer) mulai dari alamat 0 sampai 5 yang dapat digunakan HMI Droid dan SCADA.

Selanjutnya $\mathrm{rr}=$ client.read_coils $(0,4)$ merupakan range alamat digital mulai alamat 0 sampai 4 yang dapat digunakan oleh SCADA dan HMI Droid.

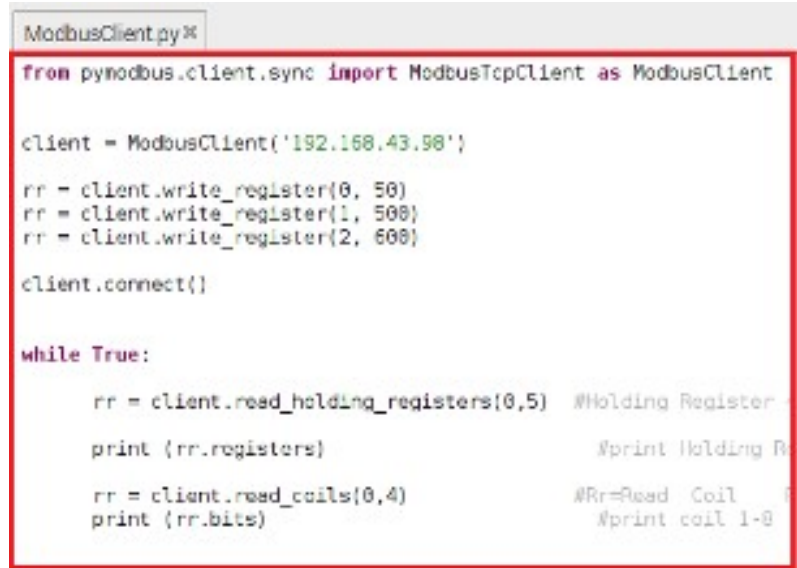

Gambar 7. Contoh penulisan Modbus client

Contoh penulisan data digital pada Modbus client terlihat pada Gambar 8.

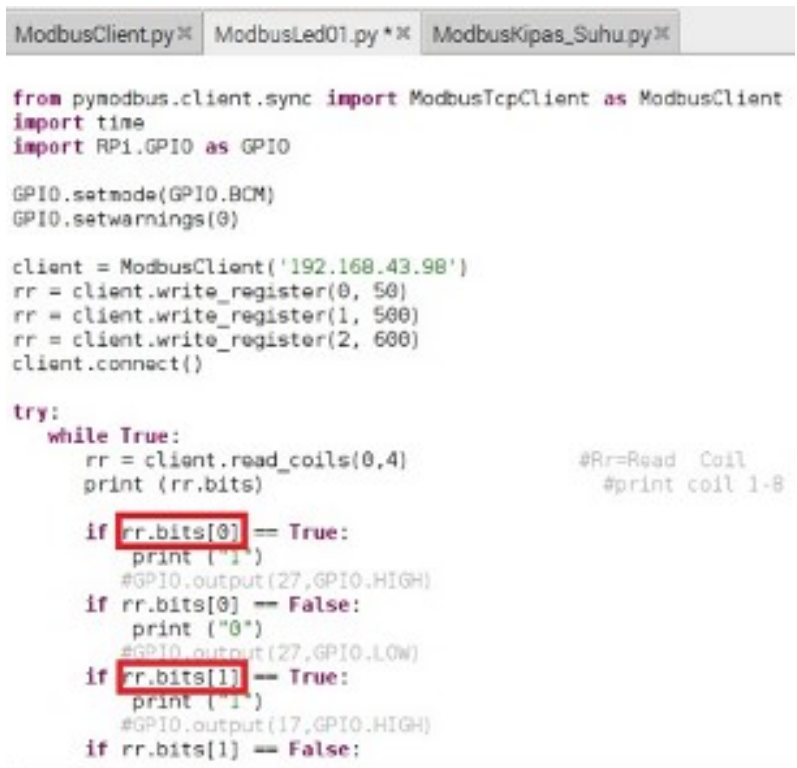

Gambar 8. Data digital pada Modbus client 
Pada Gambar 8 terlihat bahwa penulisan data digital sangat sederhana, yaitu rr.bits[0] dan rr.bits[1] sebagai alamat bit digital yang dapat digunakan HMI dan SCADA untuk mengontrol dan monitoring sistem smart home.

Untuk penulisan data analog (integer) dapat dilihat pada Gambar 9.

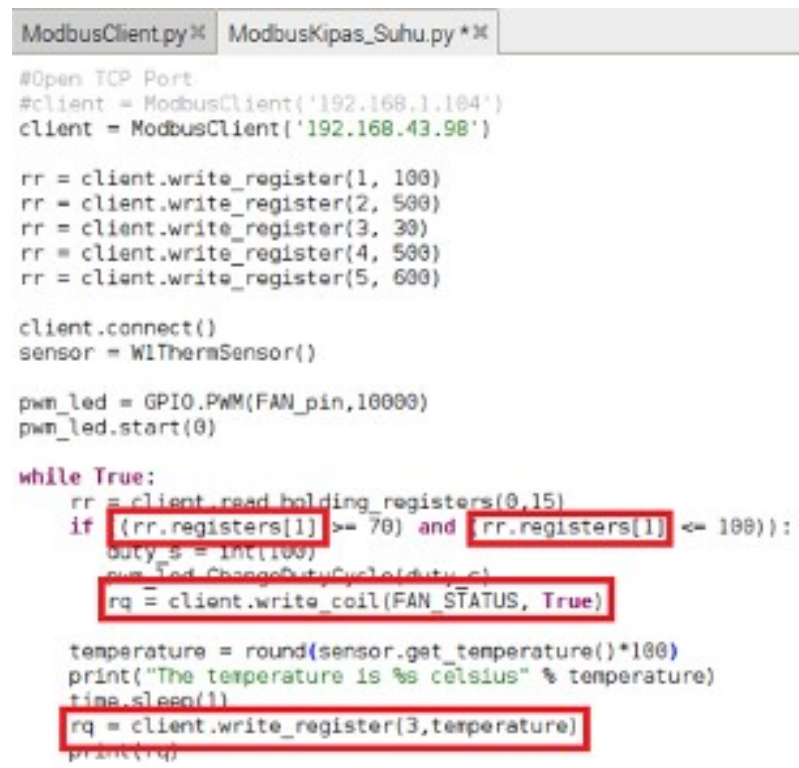

Gambar 9. Data analog pada Modbus client

Pada Gambar 9 tertulis rr.registers[1] artinya alamat analog integer yang dapat digunakan pada HMI Droid dan SCADA. Sedangkan $\mathrm{rq}=$ client.write_coil $(1$, True $)$ adalah deklarasi penulisan perintah digital, dimana 1 adalah alamat digital dan True adalah nilai dari digital. Untuk penulisan $\mathrm{rq}=$ client.write_register (3, temperature) adalah contoh deklarasi penulisan analog integer, dimana 3 sebagai alamat register dan temperatur adalah nilai analog yang didapat dari sensor suhu untuk ditampilkan pada HMI Droid dan SCADA.

Sedangkan untuk koneksi ke IoT dengan platform Cyane menggunakan GPIO pin. GPIO pada raspberry pi dihubungkan ke sensor atau perangkat lain menggunakan kabel. Pemrogaman raspberry pi dilakukan sesuai dengan deskripsi kerja yang diinginkan.
Koneksititas sistem monitor multiplatform dilakukan menggunakan variabel jarak dengan hasil seperti Tabel 2.

Dari tabel 2 terlihat bahwa pada jarak 11 meter koneksi antara SCADA dengan kontroler terputus, untuk HMI droid mengalami gangguan koneksi saat jarak 13 meter. Kedua hal tersebut terjadi karena SCADA dan HMI droid menggunakan komunikasi modbus TCP dengan wifi sebagai media komunikasinya, sehingga komunikasi hanya bisa dilakukan dengan jarak-jarak tertentu karena kemampuan setiap device untuk menangkap sinyal wifi berbeda-beda. Sedangkan untuk web cayenne dapat terus berkomunikasi dengan kontroller walaupun pada jarak 19 meter bahkan lebih karena media komunikasi yang gunakan adalah internet. Selama provider internet yang digunakan memiliki kualitas yang baik maka komunikasi pun akan tetap baik.

Tabel 2. Hasil pengujian koneksitas sistem monitor multiplatform

\begin{tabular}{|c|c|c|c|c|l|}
\hline \multirow{2}{*}{ No } & \multirow{2}{*}{$\begin{array}{c}\text { Jarak } \\
\text { pengujian } \\
\text { (meter) }\end{array}$} & $\begin{array}{c}\text { SCADA } \\
\text { Vijeo } \\
\text { Citect }\end{array}$ & $\begin{array}{c}\text { HMI } \\
\text { droid }\end{array}$ & $\begin{array}{c}\text { 作 } \\
\text { Cayenne }\end{array}$ & \multicolumn{1}{|c|}{ ket } \\
\hline 1 & 1 & $\sqrt{ }$ & $\sqrt{ }$ & $\sqrt{ }$ & baik \\
\hline 2 & 3 & $\sqrt{ }$ & $\sqrt{ }$ & $\sqrt{ }$ & baik \\
\hline 3 & 6 & $\sqrt{ }$ & $\sqrt{ }$ & $\sqrt{ }$ & baik \\
\hline 4 & 9 & $\sqrt{ }$ & $\sqrt{ }$ & $\sqrt{ }$ & baik \\
\hline 5 & 11 & $\sqrt{ }$ & $\sqrt{ }$ & $\sqrt{ }$ & baik \\
\hline 6 & 13 & - & $\sqrt{ }$ & $\sqrt{ }$ & SCADA terputus \\
\hline 7 & 16 & - & - & $\sqrt{ }$ & $\begin{array}{l}\text { SCADA dan hmi } \\
\text { Droid terputus }\end{array}$ \\
\hline 8 & 19 & - & - & $\sqrt{ }$ & $\begin{array}{l}\text { SCADA dan hmi } \\
\text { Droid terputus }\end{array}$ \\
\hline
\end{tabular}

Pengujian respon time sistem monitor terhadap sinyal yang dikirim oleh kontroler terlihat pada Tabel 3.

Pada tabel 3 dapat dilihat bahwa respon time yang menghasilkan waktu delay tersingkat adalah hmi droid karena tampilan hanya berupa led saja tidak ada perubahan gambar seperti animasi pada scada. Dimana scada membutuhkan waktu untuk merubah gambar dari symbol ke symbol. Sedangkan respon time yang sangat lama ada pada web Cayenne karena web Cayenne dan Raspberry melakukan pertukaran dengan konektifitas 
internet. Sehingga sinyal internet sangat mempengaruhi kecepatan komunikasinya.

Tabel 3. Hasil respon time sistem monitor

\begin{tabular}{|c|l|c|c|c|}
\hline \multirow{2}{*}{ No } & \multicolumn{2}{|c|}{ Command } & \multicolumn{3}{|c|}{ Response Time } \\
\cline { 3 - 5 } & & SCADA & $\begin{array}{c}\text { HMI } \\
\text { droid }\end{array}$ & $\begin{array}{c}\text { Web } \\
\text { Cayenne }\end{array}$ \\
\hline 1 & $\begin{array}{l}\text { Button on lampu } \\
\text { ruang masak }\end{array}$ & $00.42 \mathrm{~s}$ & $00.19 \mathrm{~s}$ & $07.81 \mathrm{~s}$ \\
\hline 2 & $\begin{array}{l}\text { Button off lampu } \\
\text { ruang masak }\end{array}$ & $00.64 \mathrm{~s}$ & $00.18 \mathrm{~s}$ & $10.20 \mathrm{~s}$ \\
\hline 3 & $\begin{array}{l}\text { Button on lampu } \\
\text { ruang mandi }\end{array}$ & $00.48 \mathrm{~s}$ & $00.18 \mathrm{~s}$ & $05.19 \mathrm{~s}$ \\
\hline 4 & $\begin{array}{l}\text { Button off lampu } \\
\text { ruang mandi }\end{array}$ & $00.61 \mathrm{~s}$ & $00.19 \mathrm{~s}$ & $05.87 \mathrm{~s}$ \\
\hline 5 & $\begin{array}{l}\text { Button on lampu } \\
\text { ruang tidur }\end{array}$ & $00.66 \mathrm{~s}$ & $00.19 \mathrm{~s}$ & $04.48 \mathrm{~s}$ \\
\hline 6 & $\begin{array}{l}\text { Button off lampu } \\
\text { ruang tidur }\end{array}$ & $00.56 \mathrm{~s}$ & $00.20 \mathrm{~s}$ & $07.53 \mathrm{~s}$ \\
\hline 7 & $\begin{array}{l}\text { Button power } \\
\text { outlet ON }\end{array}$ & $00.62 \mathrm{~s}$ & $00.17 \mathrm{~s}$ & $02.13 \mathrm{~s}$ \\
\hline 8 & $\begin{array}{l}\text { Button power } \\
\text { outlet OFF }\end{array}$ & $00.59 \mathrm{~s}$ & $00.18 \mathrm{~s}$ & $06.44 \mathrm{~s}$ \\
\hline 9 & Button door lock & $02.79 \mathrm{~s}$ & $02.29 \mathrm{~s}$ & $03.37 \mathrm{~s}$ \\
\hline 10 & Button unlock door & $02.38 \mathrm{~s}$ & $02.11 \mathrm{~s}$ & $02: 44 \mathrm{~s}$ \\
\hline 11 & $\begin{array}{l}\text { Button unlock door } \\
\text { (maket) }\end{array}$ & $01.75 \mathrm{~s}$ & $01.17 \mathrm{~s}$ & $04: 54 \mathrm{~s}$ \\
\hline 12 & $\begin{array}{l}\text { RFID unlock door } \\
\text { (maket) }\end{array}$ & $00.53 \mathrm{~s}$ & $00.39 \mathrm{~s}$ & $03: 04 \mathrm{~s}$ \\
\hline & & & \\
\hline
\end{tabular}

\section{KESIMPULAN}

Kesimpulan yang dapat diambil dari penelitian "Sistem Otomasi Smart Home Berbasis Internet of Things (IoT)" adalah bahwa:

1. Miniatur Smart Home yang dirancang telah dapat bekerja dengan baik sesuai dengan deskripsi kerja sistem.

2. Raspberry pi sebagai controller mampu mengintegrasikan sistem monitoring multiplatform yaitu SCADA, HMI Droid, Website IoT platform Cayanne.

3. Media komunikasi antara smart home dengan SCADA dan HMI Droid menggunakan wireless yaitu wifi dengan protocol komunikasi Modbus TCP/IP

4. Media komunikasi antara smart home dengan Web Cayenne menggunakan internet dengan koneksi GPIO.

5. Konektifitas SCADA dan HMI terputus pada jarak lebih dari 11 meter, sedangkan web IoT dapat terus berfungsi tanpa ada hambatan jarak selama terkoneksi dengan internet.
6. Rata-rata respon time pada web cayenne 6.55 detik, HMI droid 0,50 detik, dan SCADA 0,77 detik.

\section{UCAPAN TERIMAKASIH}

Puji syukur penulis panjatkan kepada Allah SWT, karena atas berkat dan rahmatNya, penulis dapat menyelesaikan penelitian yang berjudul "Sistem Otomasi Smart Home Berbasis Internet Of Things (IOT)". Kemudian, penulis mengucapkan terimakasih kepada Politeknik Negeri Jakarta (PNJ) yang telah membantu dalam bentuk dana penelitian sehingga penelitan dapat diselesaikan.

\section{DAFTAR PUSTAKA}

[1] S. Kumar, "Ubiquitous Smart Home System Using Android Application," IJCNC, vol. 6, no. 1, pp. 33-43, 2014.

[2] Dias Prihatmoko, "Pemanfaatan Raspberry Pi Sebagai Server Web Untuk Penjadwalan Kontrol Lampu Jarak Jauh" Jurnal Infotel Vol.9 No.1 Februari 2017

[3] Erick Fernando, "Automatisasi Smart Home Dengan Raspberry". Konferensi Nasional Ilmu Komputer (KONIK) 2014.

[4] Fauzan Masykur, Fiqiana Prasetiyowati, "Aplikasi Rumah Pintar (Smart Home) Pengendali Peralatan Elektronik Rumah Tangga Berbasis Web”, Jurnal Teknologi Informasi dan Ilmu Komputer (JTIIK) Vol. 3, No. 1, Maret 2016, hlm. 51-58

[5] Adhi Krisnawan, "Perancangan Sistem Keamanan Ruangan Menggunakan Raspberry Pi", e-Proceeding of Engineering : Vol.2, No.2 Agustus 2015

[6] Hermawan Arif Budiantoro, Enny Itje Sela, "Akses Kontrol Pintu Garasi Otomatis Menggunakan Raspberry Pi Berbasis Android", JURNAL TeknoSAINS Seri Teknik Komputer, 2018

[7] M. Al-Kuwari, A. Ramadan, Y. Ismael, L. Al-Sughair, A. Gastli and M. Benammar, "Smart-home automation using IoT-based sensing and monitoring platform," IEEE 12th International Conference on Compatibility, Power Electronics and 
Power Engineering (CPE-POWERENG 2018), Doha, 2018, pp. 1-6.

[8] Shouran, Zaied \& Ashari, Ahmad \& Priyambodo, Tri, "Internet of Things (IoT) of Smart Home: Privacy and Security", International Journal of Computer Applications. 182. 3-8. 10.5120/ijca2019918450.

[9] K. Haribabu, S.V.S. Prasad and M. Satish Kumar, "An IOT Based Smart Home Automation Using LabVIEW", Journal of Engineering and Applied Sciences, 13: 1421-1424, 2018 